OUTCOMES OF

MITRAL VALVE

SURGERY

\title{
Peri-operative outcomes of mitral valve surgery at Charlotte Maxeke Johannesburg Academic Hospital
}

Tebogo Mokotong-Mosekama Tabane*, Tristan Leonard" and Thomas Kleyenstuber*

\section{"Department of Anaesthesia, Rahima Moosa Mother and Child Hospital, University of the Witwatersrand, Johannesburg, South Africa \\ "Department of Anaesthesia. Chris Hani Baragwanath Academic Hospital, University of the Witwatersrand, Johannesburg, South Africa}

\author{
Address for correspondence: \\ DrTebogo Mokotong-Mosekama Tabane \\ Department of Anaesthesia \\ Rahima Moosa Mother and Child Hospital \\ University of the Witwatersrand \\ Johannesburg \\ 2000 \\ South Africa
}

Email:

tebogo.tabane@gmail.com

\section{INTRODUCTION}

Distribution and determinants of heart disease vary greatly between high-income countries and sub-Saharan Africa where rheumatic heart disease (RHD) is a major public health challenge. (I) RHD is the predominant cause of valve disease in Africa, ${ }^{(2)}$ resulting in Africa having the highest prevalence of cardiac disease in children and young adults.(1) Cumulative effects of poverty, social instability and lack of infrastructure, resources and awareness contribute to the underestimated impact of RHD. (1, 2) Studies from Africa confirm that RHD is the main cause of cardiac morbidity and mortality from heart surgery. ${ }^{(1-3)}$

Mitral valve disease, in the form of mitral stenosis and mitral regurgitation, is the commonest form of valve disease and its treatment usually involves surgical repair or replacement. These surgical procedures are highly invasive and not without risk of complications. ${ }^{(3)}$ In South Africa, data on the management and outcomes of mitral valve surgery are limited. ${ }^{(4)}$ Operative mortality in mitral valve replacement surgery is $5 \%-6 \%$ and $1 \%$ $2 \%$ in mitral valve repair. ${ }^{(5)}$ Complications associated with mitral valve surgery are commonly related to cardiopulmonary

\section{ABSTRACT}

Background: The distribution and determinants of heart disease vary greatly between high-income countries and sub-Saharan Africa where rheumatic heart disease (RHD) is a major public health challenge. Studies from Africa report that RHD is the main cause of cardiovascular morbidity and mortality in the young. Data on mitral valve surgery outcomes in South Africa are limited. The aim of this study was to describe the peri-operative outcomes of patients that have undergone mitral valve surgery at the Charlotte Maxeke Johannesburg Academic Hospital (CMJAH).

Methods: All patients older than 18 years who underwent mitral valve surgery at CMJAH between I January 2015 and 31 December 2018 were retrospectively included. Cardiac intensive care records including anaesthesia charts were assessed to describe preoperative, intra-operative and post-operative data of each patient. Pre-operative data included patient demographics and comorbidities. Intra-operative data included aortic clamp and bypass times. Post-operative variables included outcomes such as sepsis, bleeding, re-operation, and the development of acute kidney injury (AKI). The pre-operative, intra-operative and post-operative outcomes were compared to determine the effect each variable had on post-operative mortality. Results: Two hundred and seventeen patients underwent mitral valve surgery at CMJAH between I January 2015 and 31 December 2018. Four patients' records were incomplete. RHD was found to be the primary aetiology for mitral valve surgery at CMJAH with a mortality rate of $6.1 \%$. Pre-operative findings that contributed to mortality were: EuroSCORE $>2 \%$, preoperative ventilation, dialysis dependence, pre-operative inotropic support, chronic obstructive pulmonary disease, congestive cardiac failure, renal insufficiency, low ejection fraction and New York Heart Association functional class $\geq$ III. Post-operative findings that contributed to increased mortality were prolonged mechanical ventilation, pneumonia, re-operation, AKI, sepsis, bleeding, and transfusion. Increased aortic clamping and cardiopulmonary bypass times increased the risk of prolonged mechanical ventilation, re-operations, pacemaker implantations, AKI, and bleeding. Conclusions: RHD was found to be the primary aetiology for mitral valve surgery at CMJAH with a mortality of 6.1\%. Pre-operative, intra-operative and post-operative predictors of outcomes in this study confirm observations made in other parts of the world.

SAHeart 2021;1 18-125 
bypass (CPB)..(6) Platelets are activated and subsequently bind to the exposed subendothelium, the CPB circuit or to the circulating monocytes and neutrophils, resulting in a decrease in platelet numbers. (7) The decrease in platelet numbers and altered platelet function is the rationale behind the major blood loss encountered during cardiac surgery. ${ }^{(7,8)}$

Multiple studies report that CPB has negative effects on haemostasis and the inflammatory response. ${ }^{(7,9,10)}$ The blood cell activation and plasma protein alteration that occurs during CPB increases bleeding time, post-operative blood loss and increases the risk for massive blood transfusion. ${ }^{(7)}$ Bleeding occurs commonly in cardiac surgery and is a significant cause of morbidity and mortality. (I) Two to eight percent of cardiac reoperations are indicated for uncontrolled bleeding.(1-13) Prolonged cardiopulmonary bypass time (CPBT) was associated with haemostatic abnormalities.(7) CPBT $>90$ minutes resulted in higher mean blood losses peri-operatively. ${ }^{(7)}$ Reoperation in mitral valve surgery was closely linked to prolonged CPBT.(14) An African study identified CPB >120 minutes was associated with reduction in platelet counts in comparison with CPBT $<60$ minutes. ${ }^{(15)}$

In addition to the major blood loss attributed to CPB, there is a significant association with increased CPBT and the development of acute kidney injury (AKI). ${ }^{(16)} \mathrm{AKI}$ develops in $2.8 \%$ of patients following valvular heart surgery. ${ }^{(6,17)}$ In one study, $38.7 \%$ of patients who underwent mitral valve surgery had postoperative AKI, and presented with pre-operative New York Heart Association (NYHA) functional class III and IV, a dilated left ventricle (LV) and low LV ejection fraction (LVEF), all of which lead to hypoperfusion of the kidneys and AKI. ${ }^{(18)}$ AKI prolongs hospital stay and increases the risk of infectious complications and mortality. ${ }^{(17,18)}$ Risk of infection significantly increases with prolonged CPBT.(10,14) Prolonged CPBT resulted in an increased incidence of prolonged mechanical ventilation, increasing the post-operative risk of pneumonia and perioperative infection. ${ }^{(19)}$ Surgical site infection due to prolonged CPBT ranges from $0.3 \%$ - 8\%. ${ }^{(20,21)}$ Patients who developed post-operative infection had prolonged CPB and operative times. ${ }^{(20)}$ Shorter operative times, higher haemoglobin $(\mathrm{Hb})$ and higher haematocrit significantly decreased the post-operative risk of infection. The incidence of post-operative infection was $4.5 \%$. $^{(20)}$

Despite advances in surgical techniques, anaesthesia and critical care, cardiac surgery is associated with high peri-operative risk. Risk stratification scores in cardiac surgery are sophisticated and are used worldwide to determine peri-operative risk. ${ }^{(22)}$
The European System for Cardiac Operative Risk Evaluation II (EuroSCORE II) has been validated in the UK, Europe and North America, ${ }^{(22)}$ and shown to be predictive of peri-operative outcomes in cardiac surgery. ${ }^{(23)}$ However, data from Africa describing the ability of risk scoring systems to predict perioperative outcomes in African patients undergoing cardiac surgery have not been validated. ${ }^{(22,24)}$ Anaesthesiologists need to assess symptom severity and effort tolerance pre-operatively to determine risk. Advanced NYHA functional class was a risk factor for early mortality. ${ }^{(26,27)}$ Therefore, the aim of this study was to describe the peri-operative outcomes of patients that have undergone mitral valve surgery at the Charlotte Maxeke Johannesburg Academic Hospital (CMJAH).

\section{METHODS}

This study was a retrospective, descriptive review of all patients who underwent mitral valve surgery at $\mathrm{CMJAH}$ between I January 2015 and 31 December 2018. A maximum of 60 patients undergo mitral valve surgery per annum at $\mathrm{CMJAH}$. All patients above the age of 18-years-old were included in the study. Cardiac intensive care unit records including anaesthesia charts were assessed to describe preoperative, intra-operative and post-operative data of each patient included in the study. Pre-operative data included patient demographics and comorbidities. Intra-operative data included aortic clamp and bypass times. Post-operative variables assessed included outcomes such as sepsis, bleeding, re-operation and the development of AKI. The pre-operative, intra-operative and post-operative outcomes were then compared to determine the effect each variable had on postoperative mortality.

STATA (version 15) was used to analyse the data. Descriptive statistics were used for pre-operative, intra-operative and postoperative data. Categorical variables were described using frequencies and percentages. Inferential statistics were used to compare different variables. A p-value $<0.05$ was deemed statistically significant. The effect of categorical variables (preoperative demographics and post-operative outcomes) on mortality were analysed using the Fishers exact test due to the limited sample size. The Shapiro-Wilk test was used to test for the normality of distribution of the continuous variables (aortic clamping and bypass times). As the data was not normally distributed, medians and inter-quartile ranges were used to describe the continuous variables. The two-sample Wilcoxon Rank-Sum Mann-Whitney test was used to compare variables. 
Approval (M220343) from the Human Research and Ethics Committee (Medical) and all other relevant authorities was obtained. Data was managed according to the standards stipulated by the University of the Witwatersrand. RedCap ${ }^{\circledR}$ was the data management tool used to obtain information. Each patient was assigned a study number and a separate list of patient details was available only to the researcher.

\section{RESULTS}

Two hundred and seventeen patients underwent mitral valve surgery at CMJAH between I January 2015 and 31 December 2018. Four of the patients had incomplete records, therefore 213 were included in the study. The pre-operative demographic data of these patients is described in Table I. One hundred and thirty five patients (63.4\%) were female and 78 were male; $86.2 \%$ were $<60$ years of age. A large group of patients, 135 (63.4\%) did not have a documented EuroSCORE II. Of those with a documented EuroSCORE II, 7I (91\%) had a score $<2 \%, 6(7.7 \%)$ had scores between $2 \%-5 \%$ and I (1.3\%) had a score $>5 \%$. Patients' pre-operative comorbidities are described in Table II. One hundred and eighty two patients (95.8\%) had LVEF $>35 \%$. One hundred and fifty two (77.6\%) had pulmonary artery pressures (PAP) $>30 \mathrm{mmHg}$. RHD was diagnosed in 119 (55.9\%) as the primary aetiology for patients undergoing mitral valve surgery. Ischaemic mitral regurgitation (IMR) was diagnosed in 81 (38\%) as the main secondary aetiology. Sixty two (29.7\%) patients had hypertension, 38 (22.2\%) had NYHA functional class $\geq 11$, 3 I ( I 5\%) had previous cardiac surgery, 30 (14.4\%) had hypercholesterolaemia and 30 (14.4\%) had congestive cardiac failure. Serum creatinine

\begin{tabular}{|c|c|c|c|}
\hline Demographics & Variable & Frequency & Missing data \\
\hline \multirow{3}{*}{ EuroScore II (\%) } & $<2 \%$ & $7 \mid(91.03)$ & \multirow{3}{*}{135} \\
\hline & $2 \%-5 \%$ & $6(7.69)$ & \\
\hline & $>5 \%$ & I (1.28) & \\
\hline \multirow{2}{*}{$\begin{array}{l}\text { Age Group } \\
\text { (years) }\end{array}$} & $<60$ & $175(82.16)$ & \multirow[t]{2}{*}{0} \\
\hline & $>60$ & $38(17.84)$ & \\
\hline \multirow{2}{*}{ Sex } & Male & 78 (36.62) & \multirow[t]{2}{*}{0} \\
\hline & Female & 135 (63.38) & \\
\hline \multirow{3}{*}{$\mathrm{BMI}\left(\mathrm{kg} / \mathrm{m}^{2}\right)$} & $<20$ & I (0.49) & \multirow{3}{*}{7} \\
\hline & $21-34$ & $196(95.61)$ & \\
\hline & $>35$ & $8(3.90)$ & \\
\hline
\end{tabular}

TABLE II: Pre-operative comorbidities.

\begin{tabular}{|c|c|c|c|}
\hline Cardiac history & Variable & Frequency & $\begin{array}{c}\text { Missing } \\
\text { data }\end{array}$ \\
\hline \multirow{2}{*}{$\begin{array}{l}\text { Previous cardiac } \\
\text { surgery }\end{array}$} & No & $177(85.10)$ & \multirow{2}{*}{5} \\
\hline & Yes & $31(14.9)$ & \\
\hline \multirow{2}{*}{ Unstable angina } & No & $204(99.03)$ & \multirow{2}{*}{7} \\
\hline & Yes & $2(0.97)$ & \\
\hline \multirow{2}{*}{ LV dysfunction } & No & $186(89.86)$ & \multirow{2}{*}{6} \\
\hline & Yes & $21(10.14)$ & \\
\hline \multirow{2}{*}{$\begin{array}{l}\text { Recent myocardial } \\
\text { infarct }\end{array}$} & No & 205 (99.5I) & \multirow{2}{*}{7} \\
\hline & Yes & I $(0.49)$ & \\
\hline \multirow{2}{*}{ Hypercholesterolaemia } & No & $179(85.65)$ & \multirow{2}{*}{4} \\
\hline & Yes & $30(14.35)$ & \\
\hline \multirow{2}{*}{ Ischaemic heart disease } & No & $197(95.63)$ & \multirow{2}{*}{7} \\
\hline & Yes & $9(4.37)$ & \\
\hline \multirow{2}{*}{ Hypertension } & No & I 47 (70.33) & \multirow{2}{*}{9} \\
\hline & Yes & $62(29.67)$ & \\
\hline \multirow{2}{*}{$\begin{array}{l}\text { Congestive cardiac } \\
\text { failure }\end{array}$} & No & 178 (85.58) & \multirow{2}{*}{5} \\
\hline & Yes & $30(14.42)$ & \\
\hline \multirow{2}{*}{ LVEF } & No & $8(4.21)$ & \multirow{2}{*}{23} \\
\hline & Yes & I 82 (95.79) & \\
\hline \multirow{5}{*}{ Aetiology (primary) } & RHD & 119 (58.33) & \multirow{5}{*}{9} \\
\hline & Myxomatous & $13(6.37)$ & \\
\hline & Endocarditis & $19(9.31)$ & \\
\hline & MV prolapse & $28(13.37)$ & \\
\hline & Other & $25(12.25)$ & \\
\hline \multirow[t]{3}{*}{ Aetiology (secondary) } & $\begin{array}{c}\text { IMR } \\
\text { (Ischaemic } \\
\text { mitral } \\
\text { regurgitation) }\end{array}$ & |8| (88.73) & \multirow[t]{3}{*}{9} \\
\hline & DCMO & $4(1.96)$ & \\
\hline & Other & $19(9.31)$ & \\
\hline \multirow{2}{*}{ NYHA functional class } & $<$ Class III & $133(77.78)$ & \multirow{2}{*}{42} \\
\hline & $\geq$ Class III & $38(22.22)$ & \\
\hline \multirow{2}{*}{ Smoker } & No & $190(91.35)$ & \multirow{2}{*}{5} \\
\hline & Yes & I 8 (8.65) & \\
\hline \multirow{2}{*}{ COPD } & No & $194(92.82)$ & \multirow{2}{*}{4} \\
\hline & Yes & $15(7.18)$ & \\
\hline Pulmonary arterial & $<30$ & $44(22.45)$ & 17 \\
\hline pressure $(\mathrm{mmHg})$ & $>30$ & $152(77.55)$ & 11 \\
\hline Crum scontinin & $<\mid 10 \mu \mathrm{mol} / \mathrm{L}$ & $180(88.24)$ & 0 \\
\hline serum creatinine & $>1 \mid 0 \mu \mathrm{mol} / \mathrm{L}$ & $24(11.76)$ & 7 \\
\hline Kidnoudicones & No & $177(88.94)$ & 4 \\
\hline Rianey alsease & Yes & $22(11.06)$ & 14 \\
\hline
\end{tabular}


$>$ I 1 $0 \mu \mathrm{mol} / \mathrm{L}$ was observed in 24 (1 I.8\%) patients, 22 ( I I.1\%) had abnormal renal function, and 21 ( $10.1 \%$ ) presented with LV dysfunction. 18 (8.7\%) were smokers and 15 (7.2\%) presented with pre-operative chronic obstructive pulmonary disease (COPD). Diabetes was present in 21 (10.2\%) patients and 9 (4.4\%) patients had ischaemic heart disease.

One hundred and five patients (75\%) were started on inotropic support and 48 (35.9\%) had intra-operative blood transfusions. The mean aortic clamping and bypass time were 97.01 and 144.19 minutes, respectively.

Arrythmias were documented in 113 (54.1\%) patients, 4I (19.3\%) were transfused post-operatively, and AKI was present in 36 (17\%) - Table III. Twenty-eight (18.2\%) had significant bleeding and 27 (12.7\%) had prolonged mechanical ventilation. Re-operations were done in 26 (12.2\%) patients, 26 (12.4\%) had pacemakers implanted post-operatively, 24 (11.5\%) had sepsis, and cerebrovascular accidents (CVA) were noted in 13 (6.1\%) patients. 13 (6.1\%) patients died, 9 (4.3\%) developed pneumonia and I (0.5\%) patient had hypertension postoperatively.

Pre-operative data that was associated with mortality included dialysis dependence, pre-operative inotropic support, preoperative ventilation, LVEF <35\%, COPD, NYHA functional class $\geq I I$, renal insufficiency, cardiac failure, and a EuroSCORE ॥ $>2 \%$ - Table IV. Post-operative features that were independent risk factors for mortality were prolonged mechanical ventilation, re-operation, bleeding, transfusion, $\mathrm{AKI}$, sepsis, and pneumonia - Table $V$. Results from univariate analysis showed no significant association between aortic clamping time and post-operative outcomes. However, CPBT had a significant influence on post-operative outcomes. Post-operative variables associated with increased CPBT were prolonged mechanical ventilation, re-operation, pacemaker use, AKI and bleeding Table VI.

\section{DISCUSSION}

Published data approximate the peri-operative mortality rate of mitral valve surgery to be $3 \%$, dependent on the population and the peri-operative risk of the patient prior to surgery. ${ }^{(3,28)}$ In contrast to internationally published data, our peri-operative mortality rate was $6.1 \%$. RHD is the main form of valve heart disease in Africa. Multiple studies across Africa confirm that $\mathrm{RHD}$ is the primary cause of morbidity and mortality seen in younger populations undergoing cardiac surgery. (2) Findings from our study are consistent with other data from Africa, where RHD is the primary indication for mitral valve surgery, commonly performed in patients below the age of 60 years.

\begin{tabular}{|c|c|c|c|}
\hline \multicolumn{4}{|c|}{$\begin{array}{l}\text { TABLE III: Post-operative outcomes not } \\
\text { pre-operative outcomes. }\end{array}$} \\
\hline Variable & Class & Frequency & $\begin{array}{c}\text { Missing } \\
\text { data }\end{array}$ \\
\hline \multirow{2}{*}{ Arrythmias } & No & $96(45.93)$ & \multirow{2}{*}{4} \\
\hline & Yes & 113 (54.07) & \\
\hline \multirow{2}{*}{$\begin{array}{l}\text { Prolonged mechanical } \\
\text { ventilation }\end{array}$} & No & I 85 (87.26) & \multirow{2}{*}{1} \\
\hline & Yes & $27(12.74)$ & \\
\hline \multirow{2}{*}{ Pneumonia } & No & 202 (95.73) & \multirow{2}{*}{2} \\
\hline & Yes & $9(4.27)$ & \\
\hline \multirow{2}{*}{ CVA } & No & 199 (93.87) & \multirow{2}{*}{1} \\
\hline & Yes & $13(6.13)$ & \\
\hline \multirow{2}{*}{ Re-operation } & No & I 87 (87.79) & \multirow{2}{*}{0} \\
\hline & Yes & $26(12.21)$ & \\
\hline \multirow{2}{*}{ Pacemaker insertion } & No & $184(87.62)$ & \multirow{2}{*}{3} \\
\hline & Yes & $26(12.38)$ & \\
\hline \multirow{2}{*}{$\begin{array}{l}\text { PAP (pulmonary artery } \\
\text { pressure) }\end{array}$} & No & $5(41.67)$ & \multirow{2}{*}{201} \\
\hline & Yes & $7(58.33)$ & \\
\hline \multirow{2}{*}{ HPT } & No & 210 (99.53) & \multirow{2}{*}{2} \\
\hline & Yes & I (0.47) & \\
\hline \multirow{2}{*}{ AKI } & No & $176(83.02)$ & \multirow{2}{*}{ I } \\
\hline & Yes & $36(16.98)$ & \\
\hline \multirow{2}{*}{ Sepsis } & No & $186(88.57)$ & \multirow{2}{*}{3} \\
\hline & Yes & $24(11.53)$ & \\
\hline \multirow{2}{*}{ Death } & No & $200(93.90)$ & \multirow{2}{*}{0} \\
\hline & Yes & $13(6.10)$ & \\
\hline \multirow{2}{*}{ Bleeding } & No & 185 (86.85) & \multirow{2}{*}{0} \\
\hline & Yes & $28(18.15)$ & \\
\hline \multirow{2}{*}{ Transfusion } & No & $17 \mid(80.66)$ & \multirow{2}{*}{1} \\
\hline & Yes & $41(19.34)$ & \\
\hline
\end{tabular}

Advanced age and NYHA class $\geq 111$ have been shown to increase peri-operative mortality of valve surgery. ${ }^{(26,27,29)}$ Our study did not show age having a direct effect on peri-operative mortality but confirmed that NYHA class $\geq 11$ is an independent risk factor for mortality, likely due to more patients in our study being younger than 60 years and a relatively small sample size. We also found that LVEF $<35 \%$ was a strong predictor of mortality, confirming the importance of pre-operative echocardiography and functional assessment of the patient. An increase in mortality was noted in patients presenting preoperatively with COPD, heart failure and need for inotropic support. A limitation of our study is the lack of documentation of the rationale for pre-operative inotropic support. It was 
TABLE IV: Association between pre-operative factors and mortality.

\begin{tabular}{|c|c|c|c|c|}
\hline Variable & Class & Dead n (\%) & Alive $\mathrm{n}(\%)$ & $\mathrm{P}$-value \\
\hline \multirow{3}{*}{ EuroScore } & $<2 \%$ & I (I.4I) & $70(98.59)$ & \multirow{3}{*}{0.020} \\
\hline & $2-5 \%$ & $2(3.33)$ & $4(66.7)$ & \\
\hline & $>5 \%$ & $0(0.00)$ & I (I00.00) & \\
\hline \multirow{2}{*}{ Pre-operative ventilation } & No & $8(3.96)$ & $194(96.04)$ & \multirow{2}{*}{0.028} \\
\hline & Yes & $2(33.33)$ & $4(66.67)$ & \\
\hline \multirow{2}{*}{ Dialysis dependent } & No & $9(4.35)$ & $198(95.65)$ & \multirow{2}{*}{0.048} \\
\hline & Yes & I (100.00) & $0(0.00)$ & \\
\hline \multirow{2}{*}{ Pre-operative inotropic support } & No & $7(3.45)$ & $196(96.55)$ & \multirow{2}{*}{0.01} \\
\hline & Yes & $2(50.00)$ & $2(50.00)$ & \\
\hline \multirow{2}{*}{ PAP $(\mathrm{mmHg})$} & $<30$ & $4(9.09)$ & $40(90.91)$ & \multirow{2}{*}{0.27} \\
\hline & $>30$ & $7(4.61)$ & I 45 (95.39) & \\
\hline \multirow{2}{*}{ LV dysfunction } & No & $8(4.30)$ & $178(95.70)$ & \multirow{2}{*}{0.27} \\
\hline & Yes & $2(9.52)$ & $19(90.48)$ & \\
\hline \multirow{2}{*}{ Smoker } & No & $9(4.74)$ & |8| (95.26) & \multirow{2}{*}{0.60} \\
\hline & Yes & I (5.56) & $17(94.44)$ & \\
\hline \multirow{2}{*}{ COPD } & No & $8(4.12)$ & 186 (95.88) & \multirow{2}{*}{0.035} \\
\hline & Yes & $3(20.00)$ & $12(80.00)$ & \\
\hline \multirow{2}{*}{ CCF } & No & $4(2.25)$ & $174(97.75)$ & \multirow{2}{*}{0.004} \\
\hline & Yes & $5(16.67)$ & $25(83.33)$ & \\
\hline \multirow{2}{*}{ Renal insufficiency } & No & $5(2.82)$ & $172(97.18)$ & \multirow{2}{*}{0.046} \\
\hline & Yes & $3(18.64)$ & $19(86.36)$ & \\
\hline \multirow{2}{*}{ EF\% } & $<35 \%$ & $2(25.00)$ & $6(75.00)$ & \multirow{2}{*}{0.03} \\
\hline & $>35 \%$ & $5(2.75)$ & $177(97.25)$ & \\
\hline \multirow{5}{*}{ Aetiology (primary) } & RHD & $4(3.36)$ & 115 (96.64) & \multirow{5}{*}{0.043} \\
\hline & Myxomatous & $0(0.00)$ & $18(100.00)$ & \\
\hline & Endocarditis & $4(21.05)$ & $15(78.95)$ & \\
\hline & MV prolapse & $2(7.14)$ & $26(92.86)$ & \\
\hline & Other & $2(8.00)$ & $23(92.00)$ & \\
\hline \multirow{3}{*}{ Aetiology (secondary) } & IMR & $10(5.52)$ & |7| (94.48) & \multirow{3}{*}{0.29} \\
\hline & DCMO & I (25.00) & $3(75.00)$ & \\
\hline & Other & I (5.26) & $18(94.74)$ & \\
\hline \multirow{2}{*}{ NYHA } & $<$ Class 3 & $2(1.50)$ & 131 (98.50) & \multirow{2}{*}{0.006} \\
\hline & $\geq$ Class 3 & $5(18.16)$ & $33(86.84)$ & \\
\hline
\end{tabular}

difficult to determine whether inotropic support was an independent risk factor for mortality or if the pre-operative state requiring inotropic support was a greater contributor to the increase noted.

LV dysfunction, atrial fibrillation and pulmonary hypertension are identified risk factors for peri-operative morbidity and mor- tality. ${ }^{(30)}$ In our study, arrythmias and pulmonary arterial pressures $>30 \mathrm{mmHg}$ were commonly documented. A limitation of our study is that pulmonary artery pressures were only documented prior to surgery in most patients, making it difficult to assess whether increasing pressures had a direct correlation with the risk of mortality. 
TABLE V: Association between post-operative outcomes and mortality.

\begin{tabular}{|c|c|c|c|c|}
\hline Variable & Class & $\begin{array}{c}\text { Death n (\%) } \\
n=13(6.10 \%)\end{array}$ & $\begin{array}{c}\text { Alive } \mathrm{n}(\%) \\
\mathrm{n}=200(93.10 \%)\end{array}$ & P-value \\
\hline \multirow{2}{*}{ Arrythmias } & Yes & $7(6.19)$ & $106(93.81)$ & \multirow{2}{*}{1.00} \\
\hline & No & $5(5.21)$ & 91 (94.79) & \\
\hline \multirow{2}{*}{ Prolonged mechanical ventilation } & Yes & $10(37.04)$ & $17(62.96)$ & \multirow{2}{*}{$<0.01$} \\
\hline & No & $2(1.08)$ & I $83(98.92)$ & \\
\hline \multirow{2}{*}{ Pneumonia } & Yes & $3(3.33)$ & $6(66.67)$ & \multirow{2}{*}{$<0.01$} \\
\hline & No & $8(3.96)$ & 194(96.04) & \\
\hline \multirow{2}{*}{ CVA } & Yes & $2(15.38)$ & II (84.62) & \multirow{2}{*}{0.16} \\
\hline & No & $10(5.03)$ & $189(94.97)$ & \\
\hline \multirow{2}{*}{ Re-operation } & Yes & $9(34.62)$ & $17(65.38)$ & \multirow{2}{*}{$<0.01$} \\
\hline & No & $4(2.14)$ & 183(97.86) & \\
\hline \multirow{2}{*}{ Pacemaker insertion } & Yes & I (3.85) & $25(96.15)$ & \multirow{2}{*}{1.00} \\
\hline & No & $10(5.43)$ & $174(94.57)$ & \\
\hline \multirow{2}{*}{ AKI } & Yes & $7(19.44)$ & $29(80.56)$ & \multirow{2}{*}{$<0.01$} \\
\hline & No & $5(2.84)$ & $171(97.16)$ & \\
\hline \multirow{2}{*}{ Sepsis } & Yes & $7(29.17)$ & $17(70.83)$ & \multirow{2}{*}{$<0.01$} \\
\hline & No & $3(1.61)$ & I $83(98.39)$ & \\
\hline \multirow{2}{*}{ Bleeding } & Yes & $8(28.57)$ & $20(71.43)$ & \multirow{2}{*}{$<0.01$} \\
\hline & No & $5(2.70)$ & $180(97.30)$ & \\
\hline \multirow{2}{*}{ Transfusion } & Yes & $8(19.51)$ & 33 (80.49) & \multirow{2}{*}{$<0.01$} \\
\hline & No & $4(2.34)$ & $167(97.66)$ & \\
\hline
\end{tabular}

Risk scoring systems for predicting peri-operative morbidity and mortality are mandatory. ${ }^{(31)}$ There are no risk scoring systems validated in large population groups like sub-Saharan Africa. ${ }^{(22,24)}$ In our study, the EuroSCORE II was used as a pre-operative assessment to predict the risk of mortality. Unfortunately, there were many missing data and very few patient records had a documented EuroSCORE II score. We suggest that a risk scoring system be validated in Africa to assist in predicting mortality in our population.

$\mathrm{AKI}$ and its detrimental peri-operative effects during mitral valve surgery have been extensively reviewed. ${ }^{(6,16,17)}$ Patients undergoing mitral valve surgery commonly display a decrease in the volume of blood ejected from the mitral valve due to regurgitation, resulting in poor perfusion to the kidneys. A third of patients who underwent mitral valve surgery developed $A K I,{ }^{(18)}$ and patients presenting with AKI had increased prevalence of hypertension and diabetes. Although patients in our study did not have high rates of hypertension and diabetes, AKI proved to be a major independent predictor of mortality. We also found that increased CPBT of $\geq 157.5$ minutes and aortic clamping times $\geq 105.5$ minutes directly increased the risk of $\mathrm{AKI}$, which is in keeping with prior reports. ${ }^{(6,18,32)}$

Increased CPBT is an independent risk factor for bleeding and subsequent blood transfusion following cardiac surgery. ${ }^{(7,15)}$ In addition to the above findings, our study confirmed that increased CPBT and aortic clamping times increased the risk of prolonged mechanical ventilation and subsequent pneumonia. ${ }^{(19)}$ A novel finding in our series is the increased use of pacemakers associated with increased bypass and aortic clamping times. Contrary to previous studies, we did not find that sepsis was directly linked to increased CPBT and aortic clamping times. Sepsis, however, was a strong predictor of perioperative mortality seen in our study.

The economic cost of transfusing blood products and associated complications are high. ${ }^{(33)}$ The limitation in this study is that data on the number of blood products transfused was not collected nor were the negative outcomes of transfusion documented. 
TABLE VI: Association between post-operative outcomes and the intra-operative times.

\begin{tabular}{|c|c|c|c|c|c|}
\hline Variable & Class & $\begin{array}{c}\text { Aortic clamp time } \\
\text { Median (IQR) }\end{array}$ & P-value & $\begin{array}{l}\text { Bypass time } \\
\text { Median [IQR] }\end{array}$ & P-value \\
\hline \multirow{2}{*}{ Arrythmias } & No & $91(40.5)$ & 0.37 & 133(43.5) & \multirow{2}{*}{0.12} \\
\hline & Yes & $98(43)$ & & 147(55) & \\
\hline \multirow{2}{*}{ Prolonged mechanical ventilation } & No & $9 \mid(4 \mid)$ & 0.55 & $137(50.5)$ & \multirow{2}{*}{0.029} \\
\hline & Yes & 107(5I) & & I56(55) & \\
\hline \multirow{2}{*}{ Pneumonia } & No & $92(42)$ & 0.54 & $140(52)$ & \multirow{2}{*}{0.76} \\
\hline & Yes & $96.5(53)$ & & $141.5(20)$ & \\
\hline \multirow{2}{*}{ CVA } & No & $92(43)$ & 0.92 & $139(52)$ & \multirow{2}{*}{0.28} \\
\hline & Yes & $94(37)$ & & 151.5(43) & \\
\hline \multirow{2}{*}{ Re-operation } & No & $9 \mid(4 \mid)$ & 0.40 & 137(53) & \multirow{2}{*}{0.03} \\
\hline & Yes & $106(46)$ & & |46.5(66.5) & \\
\hline \multirow{2}{*}{ Pacemaker insertion } & No & $91(40)$ & 0.20 & $\mid 36(5 \mid)$ & \multirow{2}{*}{0.01} \\
\hline & Yes & 108(59) & & $157(57)$ & \\
\hline \multirow{2}{*}{ AKI } & No & $91(42)$ & 0.40 & $137(52)$ & \multirow{2}{*}{0.01} \\
\hline & Yes & $105.5(46.5)$ & & 157.5(45) & \\
\hline \multirow{2}{*}{ Sepsis } & No & $91.5(42.5)$ & 0.98 & 138(52) & \multirow{2}{*}{0.36} \\
\hline & Yes & $100(33)$ & & $\mid 47(7 \mid)$ & \\
\hline \multirow{2}{*}{ Death } & No & $92(4 I)$ & 0.66 & $|4|(52)$ & \multirow{2}{*}{0.30} \\
\hline & Yes & $86(63)$ & & $150.5(83)$ & \\
\hline \multirow{2}{*}{ Bleeding } & No & $91(42)$ & 0.15 & $137(51)$ & \multirow{2}{*}{0.02} \\
\hline & Yes & $106(5 \mathrm{I})$ & & $\mid 54(6 \mid)$ & \\
\hline \multirow{2}{*}{ Transfusion } & No & $92(40)$ & 0.93 & $140(52.5)$ & \multirow{2}{*}{0.33} \\
\hline & Yes & $98(44)$ & & $145(53)$ & \\
\hline
\end{tabular}

The peri-operative outcomes of mitral valve surgery found in this study can be avoided, anticipated, and effectively managed. A multidisciplinary team of anaesthesiologists, cardiac surgeons, physicians, nurses and allied health professionals are needed to decrease morbidity and assess each patient pre-operatively for the risk of peri-operative mortality.

\section{CONCLUSION}

RHD was the predominant primary aetiology for mitral valve surgery in our institution with an overall mortality rate of $6.1 \%$. Pre-operative findings that contributed to increased mortality were EuroSCORE $\| \geq 2 \%$, pre-operative ventilation, dialysis dependence, pre-operative inotropic support, COPD, heart failure, renal insufficiency, LVEF $<35 \%$ and NYHA $\geq 11$. Postoperative findings that contributed to increased mortality were prolonged mechanical ventilation, pneumonia, reoperation, AKI, sepsis, bleeding, and transfusion. Increased aortic clamping and CPBT significantly increased the risk of prolonged mechanical ventilation, re-operations, use of pacemakers, AKI, and bleeding.

\section{ACKNOWLEDGEMENTS}

Morelearnings Sibanda is acknowledged for his assistance in statistical analysis and Elena Liebhaber for the verification of our results.

\section{Conflict of interest: none declared.}


I. Zühlke L, Mirabel M, Marijon E. Congenital heart disease and rheumatic heart disease in Africa: Recent advances and current priorities. Heart. 2013; 99(21): |554-61.doi: 10.1 |36/heartjnl-2013-303896.

2. Nkomo VT. Epidemiology of valvular heart diseases in Africa. SA Heart. 2009;6: 12-8.doi: 10.24.24170/6-1-2006.

3. Al Naili M, Herbst PG, Doubell AF, et al. A retrospective audit of mitral valve repair surgery at Tygerberg Hospital. SA Heart. 20 I 8; 15(3): 182-9.doi: 10.24170/15-3-3182.

4. Harkey A, Kwok H, Fan K. The evolution of mitral valve surgery: The future in the hand of robots. Braz J Cardiovasc Surg. 2020;35(4):555-64.doi: 10.21470/1678-9741-2019-0192.

5. Looney Y, Quinton P. Mitral valve surgery. BJA Educ. 2005;5:199-202.doi: 10.1093/bjaceaccp/mki05।.

6. Leballo G, Chakane PM. Cardiac surgery-associated acute kidney injury: Pathophysiology and diagnostic modalities and management. Cardiovasc J Afr. 2020;3। (4):205- 12.doi: 10.5830/cvja-2019-069.

7. Jubayer Ahmed RR, Heemel Saha. Effect of cardiopulmonary bypass on haemostasis in patients undergoing cardiac surgery. Bangabandu Sheikh Mujib Med Univ J. 20 I 8; I I: I34-8.doi: 10.3329/bsmmuj.v I li2.35780.

8. McKenna R, Bachmann F, Whittaker B, et al. The haemostatic mechanism after open-heart surgery. II. Frequency of abnormal platelet functions during and after extracorporeal circulation. J Thorac Cardiovasc Surg. 1975 70(2):298-308.doi: 10.1016/50022-5223(19)40355-3.

9. Petrou A, Tzimas P, Siminelakis S. Massive bleeding in cardiac surgery Definitions, predictors and challenges. Hippokratia. 2016;20(3):179-86. doi: Available: https://www.ncbi.nlm.nih.gov/pmc/articles/PMC5654433/pdf/ hippokratia-20-179.pdf. (Accessed 20-01-2021)

10. Roy S, Saha K, Mukherjee K, et al. Activation of coagulation and fibrinolysis during coronary artery bypass grafting: A comparison between on-pump and off-pump techniques. Indian J Hematol Blood Transfus. 2014;30(4):333-4I. doi: |0.1007/s | 2288-0|3-0250-7.

II. Saber I, Omran AM, Elameen S, et al. Risk scoring for prediction of postoperative bleeding in cardiac surgery. J Egypt Soc Cardiothorac Surg. 20 18;26: 185-90.doi: 10.1016/j.jescts.2018.04.003.

12. Vivacqua A, Koch CG, Yousuf AM, et al. Morbidity of bleeding after cardiac surgery: Is it blood transfusion, reoperation for bleeding, or both? Ann Thorac Surg. 201 1;91 (6): 1780-90.doi: 10.1016/j.athoracsur.201 1.03.105.

13. van de Watering $L$, Brand $A$. Independent association of massive blood loss with mortality in cardiac surgery. Transfusion. 2005;45(7): 1235; author reply -6.doi: 10.1 I | |/j. 1537-2995.2005.00 185.x.

14. David TE. Durability of mitral valve repair for mitral regurgitation due to degenerative mitral valve disease. Ann Cardiothorac Surg. 2015;4(5):4I7-2I. doi: 10.3978/j.issn.2225-319X.2015.08.07.

15. Tettey M, Antiteye L, Sereboe F, et al. Predictors of postoperative bleeding and blood transfusion in cardiac surgery. Ghana Med J. 2009;2:71-6.doi: I0.43| 4/gmj.v43i2.55316.

16. Mao MA, Thongprayoon C, Wu Y, et al. Incidence, severity, and outcomes of acute kidney injury in octogenarians following heart valve replacement surgery. Int J Nephrol. 20 I5;20 I 5:23795 I.doi: 10.1 I55/20 I5/23795 I.

17. Rather FA, Najar SM, Malla HA, et al. Profile of acute kidney injury after open heart surgeries in a tertiary care hospital. Saudi J Kidney Dis Transpl. 2015;26(6): I 177-82.doi: 10.4103/1319-2442.168601.

18. Chang $\mathrm{CH}$, Lee CC, Chen SW, et al. Predicting Acute Kidney Injury Following Mitral Valve Repair. Int J Med Sci. 20 I6; I 3(I): 19-24.doi: 10.7| 50/ijms. 13253.

19. Nadeem R, Agarwal S, Jawed S, et al. Impact of cardiopulmonary bypass time on postoperative duration of mechanical ventilation in patients undergoing cardiovascular surgeries: A systemic review and regression of metadata. Cureus. 2019; I I ( I ):e6088.doi: 10.7759/cureus.6088.

20. Jamil DD, Baram A, Saqat BH. Impact of prolonged cardiopulmonary bypass and operative exposure time on the incidence of surgical site infections in patients undergoing open heart surgery: Single center case series. Int J Surg Open. 2020;22:55-6.doi: 10.1016/j.ijso.2019.12.001.
21. Milano CA, Kesler K, Archibald N, et al. Mediastinitis after coronary artery bypass graft surgery. Risk factors and long-term survival. Circulation. 1995; 92(8):2245-5 I.doi: |0.1 | 61/0 |.cir.92.8.2245.

22. Cornelissen $\mathrm{H}$, Arrowsmith J. Preoperative assessment for cardiac surgery. BJA Educ. 2006;6(3):109-13.doi: 10.1093/bjaceaccp/mk1013.

23. Toumpoulis I, Anagnostopoulos C, Swistel D. Does EUROscore predict length of hospital stay and specific postoperative complications after cardiac surgery? Euro J Cardiothorac Surg. 2005;27:128-33.doi: 10.1016/j.ejcts. 2004.09.020

24. Hote M. Cardiac surgery risk scoring systems: In quest for the best. Heart Asia. 2018;10.doi: 10.1136/heartasia-2018-011017

25. Kurlansky P, Soo-Hoo S, Nemeth S. East meets West: the influence of racial, ethnic and cultural risk factors on cardiac surgical risk model performance. Heart Asia. 2018;10:1-6.doi: 10.1 136.

26. Hellgren L, Kvidal P, Hörte LG, et al. Survival after mitral valve replacement: rationale for surgery before occurrence of severe symptoms. Ann Thorac Surg. 2004;78(4):1241-7.doi: 10.1016/j.athoracsur.2004.04.017

27. Fernandes AM, Andrade GM, Oliveira RM, et al. Evaluation of variables responsible for hospital mortality in patients with rheumatic heart disease undergoing double valve replacement. Rev Bras Cir Cardiovasc. 2014; 29(4):537-42.doi: 10.5935/1678-9741.20140044.

28. Chatterjee S, Rankin JS, Gammie JS, et al. Isolated mitral valve surgery risk in 77836 patients from the Society of Thoracic Surgeons database. Ann Thorac Surg. 2013;96(5):1587-94; discussion 94-5.doi: 10.1016/j. athoracsur.2013.06.051.

29. Reisman AM, Thomas AT, Boateng P, et al. Predictors of 30-day outcomes following mitral valve repair. Ann Med Surg (Lond). 2019;47:5-12.doi: 10.1016/j.amsu.2019.09.001.

30. Lombard F, Liang Y. Risk factors for mitral valve surgery: Atrial fibrillation and pulmonary hypertension. Semin Cardiothorac Vasc Anesth. 2019;23:57-69. doi: $10.1177 / 1089253218821694$.

31. Bonnet V, Boisselier C, Saplacan V, et al. The role of age and comorbidities in postoperative outcome of mitral valve repair: A propensity-matched study. Medicine. 2016;95(25):e3938.doi: 10.1097/md.0000000000003938.

32. Yamauchi T, Miyagawa S, Yoshikawa Y, et al. Risk index for postoperative acute kidney injury after valvular surgery using cardiopulmonary bypass. Ann Thorac Surg. 2017;104(3):868-75.doi: 10.1016/j.athoracsur.2017.02.012.

33. Tempe DK, Khurana P. Optimal blood transfusion practice in cardiac surgery. J Cardiothorac Vasc Anesth. 2018;32(6):2743-5.doi: 10.1053/j. jvca.2018.05.05।. 